\title{
Reproducibility and responsiveness of the Frailty Index and Frailty Phenotype in older hospitalized patients
}

Marlies Feenstra ${ }^{1,2^{*}+}$, Frederike M.M. Oud ${ }^{1,3+}$, Carolien J. Jansen ${ }^{1}$, Nynke Smidtt ${ }^{4}$, Barbara C. van Munster ${ }^{1,3}$ and Sophia E. de Rooij ${ }^{1,2}$

\begin{abstract}
Background: There is growing interest for interventions aiming at preventing frailty progression or even to reverse frailty in older people, yet it is still unclear which frailty instrument is most appropriate for measuring change scores over time to determine the effectiveness of interventions. The aim of this prospective cohort study was to determine reproducibility and responsiveness properties of the Frailty Index (FI) and Frailty Phenotype (FP) in acutely hospitalized medical patients aged 70 years and older.

Methods: Reproducibility was assessed by Intra-Class Correlation Coefficients (ICC), standard error of measurement (SEM) and smallest detectable change (SDC); Responsiveness was assessed by the standardized response mean (SRM), and area under the receiver operating characteristic curve (AUC).

Results: At baseline, 243 patients were included with a median age of 76 years (range 70-98). The analytic samples included 192 and 187 patients in the three and twelve months follow-up analyses, respectively. ICC of the FI were 0.85 (95\% confidence interval [Cl]: 0.76; 0.91) and 0.84 (95\% Cl: 0.77; 0.90), and 0.65 (95\% Cl: 0.49; 0.77) and 0.77 ( $95 \%$ Cl: 0.65 ; 0.84) for the FP. SEM ranged from 5 to $13 \%$; SDC from 13 to $37 \%$. SRMs were good in patients with unchanged frailty status $(<0.50)$, and doubtful to good for deteriorated and improved patients $(0.43-1.00)$. AUC's over three months were $0.77(95 \% \mathrm{Cl}: 0.69 ; 0.86)$ and $0.71(95 \% \mathrm{Cl}: 0.62 ; 0.79)$ for the $\mathrm{Fl}$, and $0.68(95 \% \mathrm{Cl}: 0.58 ; 0.77)$ and 0.65 (95\% Cl: $0.55 ; 0.74)$ for the FP. Over twelve months, AUCs were 0.78 (95\% Cl: $0.69 ; 0.87)$ and 0.82 (95\% Cl: 0.73 ; 0.90$)$ for the $\mathrm{Fl}$, and 0.78 ( $95 \% \mathrm{Cl}: 0.69 ; 0.87)$ and 0.75 (95\% Cl: $0.67 ; 0.84)$ for the FP.
\end{abstract}

Conclusions: The Frailty Index showed better reproducibility and responsiveness properties compared to the Frailty Phenotype among acutely hospitalized older patients.

Keywords: Frail, Psychometric properties, Measurement properties, Reliability, Internal Medicine, Geriatric care

\footnotetext{
* Correspondence: m.feenstra01@umcg.nl

${ }^{+}$Marlies Feenstra and Frederike M.M. Oud contributed equally to this work.

'Department of Internal Medicine and Geriatrics, University of Groningen,

University Medical Center Groningen, PO Box 30001, HPC: AA43, 9700 RB

Groningen, The Netherlands

${ }^{2}$ Medical Spectrum Twente Hospital, Enschede, the Netherlands

Full list of author information is available at the end of the article
}

(c) The Author(s). 2021 Open Access This article is licensed under a Creative Commons Attribution 4.0 International License, which permits use, sharing, adaptation, distribution and reproduction in any medium or format, as long as you give appropriate credit to the original author(s) and the source, provide a link to the Creative Commons licence, and indicate if changes were made. The images or other third party material in this article are included in the article's Creative Commons licence, unless indicated otherwise in a credit line to the material. If material is not included in the article's Creative Commons licence and your intended use is not permitted by statutory regulation or exceeds the permitted use, you will need to obtain permission directly from the copyright holder. To view a copy of this licence, visit http://creativecommons.org/licenses/by/4.0/ The Creative Commons Public Domain Dedication waiver (http://creativecommons.org/publicdomain/zero/1.0/) applies to the data made available in this article, unless otherwise stated in a credit line to the data. 


\section{Background}

Frailty is a medical condition of increased vulnerability and poor resolution of homeostasis after a stressor event as a consequence of cumulative decline in many physiological systems during a lifetime [1]. Around $40 \%$ of the hospitalized older patients are frail which is associated with poor health outcomes, such as functional decline, hospital re-admission, institutionalization, and mortality [2, 3].

Identifying (pre) frail older adults, and those at risk for progression of frailty is important. Some older adults may benefit from interventions targeted at prevention of frailty progression to lower the risk of poor health outcomes like functional decline [4, 5]. Reliable and valid assessment of frailty and how to measure relevant changes in frailty over time is therefore crucial.

Several frailty instruments exist for the purpose of diagnosing, risk stratification, and evaluating frailty over time [6]. Comprehensive geriatric assessment is currently the gold standard for diagnosing the frailty status in clinical practice [1], but the cumulative deficits model or Frailty Index (FI) and the Frailty Phenotype (FP) are the most widely used instruments used to establish frailty status in research $[7,8]$. Construct validity and predictive validity of negative health outcomes of the FI and FP have been extensively evaluated and are proven to be satisfactory in both community-dwelling and hospitalized older adults [9-11]. Reproducibility and responsiveness of change scores of frailty instruments are poorly studied especially after hospitalization and it is still unclear which frailty instrument is most appropriate for measuring change scores over time or the effectiveness of interventions $[9,11,12]$.

Therefore, the aim of this study is to determine the reproducibility and responsiveness of the FI and FP in acutely admitted hospitalized older medical patients.

\section{Methods}

\section{Study population}

During this monocentric prospective cohort study, patients aged $\geq 70$ years were recruited between February 2017 and May 2018. Twelve months' follow-up measurements continued to the end of April 2019. During weekdays patients admitted to surgical, cardiology, pulmonology, medical oncology, nephrology, and general internal medicine wards were checked for eligibility to participate. Inclusion criteria were age $\geq 70$ years and an expected hospital stay of at least two days. Exclusion criteria were no understanding of the Dutch language, any (temporary) cognitive condition that influenced decision making capacity, and no written informed consent. The Research Ethics Committee of the University Medical Center Groningen ruled that no formal ethics approval was required (file number: 201,600,268). All participants provided written informed consent before participation.

\section{Data collection}

Baseline assessment took place within four days after admission. Telephonic assessments were performed at three and twelve months' post-discharge, in which baseline questions were repeated and two anchor questions were added [13]. Data were collected by trained research staff.

\section{Questionnaires \\ Frailty instruments}

The FI score was calculated using 34 deficits associated with health status [14]. The FP was assessed by five selfreporting criteria including strength, walking ability, weight loss, physical activity, and exhaustion [15, 16]. A detailed description of the included items of the FI and FP are presented in Additional File 1, Tables A1 and A2.

\section{Patient-reported anchor questions}

Anchor questions were used as an external criterion for measuring responsiveness [17]. Two different anchor questions were used: (1) 'In general, how is your health state now, compared to three months/twelve months ago before hospitalization?' (2) 'In general how is your daily functioning now, compared to three months/twelve months ago before hospitalization?' Response options were a five point Likert scale. Patients were divided into three categories based on the anchor questions (improved, unchanged, and deteriorated patients). Improved was scored if a patient answered 'slightly better' or 'much better'. Unchanged was scored if the answer was 'more or less the same'. Deteriorated was scored if a patient answered 'slightly worse' or 'much worse'.

\section{Sociodemographic and patient characteristics}

For all subjects, baseline sociodemographic characteristics were collected including age, sex, living situation (independent living vs. not independent living), and educational level ( $\leq$ high school vs. $>$ high school. After discharge, medical charts were consulted to assess baseline comorbidity (Charlson Comorbidity Index) [18] and mortality during follow-up time.

\section{Statistical analysis \\ Descriptive statistics}

For all baseline sociodemographic and patient characteristics, descriptive statistics were calculated. The distribution of the scores on frailty instruments at baseline were inspected for possible floor and ceiling effects. Thresholds for floor and ceiling effects were if $\geq 15 \%$ of the patients achieved the lowest or highest possible score, respectively [19]. 


\section{Reproducibility}

Test-retest reproducibility was assessed among patients who reported to be unchanged according to the anchor question three months post discharge. The following parameters were calculated:

- The intraclass correlation coefficient (ICC) using a two-way mixed effects model for absolute agreement was used for the baseline and three months followup measurements of the FI and the FP. Cut-off values for interpretation of the ICC including the $95 \%$ confidence interval were $<0.5$ poor, $\geq 0.5$ and $<0.75$ moderate, $\geq 0.75$ and $<0.9$ good, $\geq 0.9$ excellent reliability [20].

- Cohen's kappa and absolute agreement were calculated to assess the reproducibility of the FP using the categorized outcome (robust, prefrail, frail). Cut-off values were $<0.40$ poor, $\geq 0.40$ and $<$ 0.75 fair to good, $\geq 0.75$ excellent agreement [19].

- Measurement error of the FI and FP was assessed by calculating Bland-Altman plots and the standard error of measurement (SEM). Bland-Altman plots were calculated by the mean change scores of baseline and three months post discharge assessments plotted against the difference on both scores. SEM was calculated using the following formula: $\mathrm{SEM}=$ $\mathrm{SD}(\mathrm{T} 0) \times \sqrt{ }(1-\mathrm{r})$. SD is the standard deviation of the baseline measurement of the Frailty Index of the unchanged group; $r$ refers to the ICC. To interpret the SEM, scores are converted to percentages of the scale range. Cut-off values were: $\leq 5 \%$ very good, $\leq 10 \%$ good, $>10 \%$ and $<20 \%$ doubtful, $\geq$ $20 \%$ poor [21].

- To be able to interpret change scores, the smallest detectable change (SDC) was calculated for the FI and FP using continuous scores. SDC reflects the variance of the distribution of change scores among stable patients. Patients who reported no change according to the anchor question were assumed to be stable. SDC was calculated by the following formula: $\mathrm{SDC}=1.96 \times \sqrt{2} \times \mathrm{SEM}$ [21]. Both the absolute SDC value as well as the SDC as a percentage of the scale range were calculated.

\section{Responsiveness}

Two types of responsiveness were determined over the timeframes from pre-hospital admission to three and twelve months' post discharge:

1. Internal responsiveness, defined as the magnitude of change related to the variance in change scores, was determined by the standardized response mean (SRM). SRM is calculated by dividing the mean change score by the standard deviation of the mean change score [22]. SRMs were separately calculated for improved, unchanged, and deteriorated patients according to the anchor question for both the FI and FP using continuous scores. Cut-off values were: $\leq 0.2$ small, $>0.2$ and $\leq 0.5$ doubtful, $>0.5$ and $\leq 0.8$ good, $>0.8$ very good internal responsiveness for the improved and deteriorated patients; $<0.50$ good, $\geq 0.50$ small for the unchanged patients [22].

2. External responsiveness, defined as the ability to detect change over time in the construct to be measured, was assessed by investigating the ability of the instruments to discriminate between relevant changes (improved and deteriorated patients) and irrelevant changes (unchanged patients) [19]. This is reflected by the area under the receiver operating characteristic curve (AUC). For these analyses, the anchor question was considered as the gold standard for change, and the change scores on the FI and FP using continuous scores were considered as the 'diagnostic test' for measuring change. An AUC of $\geq 0.70$ was considered to be adequate. In addition, for each instrument the optimal cut-off point was calculated for which the sensitivity and specificity together revealed the least error in classifying patients as improved versus unchanged and deteriorated versus unchanged. To carry out these analyses, the correlation (Spearman's rho) between the change score on the frailty instrument and the anchor question should be at least 0.40 [23].

\section{Missing data and sensitivity analysis}

Patients who died during follow-up were included in the analytic sample by imputing the highest prevalent frailty category for each frailty instrument and the worst outcome for the anchor questions. A complete case analysis was included as a sensitivity analysis. For all analyses IBM SPSS Statistics, version 23 was used.

\section{Results \\ Descriptive statistics}

Baseline characteristics were presented in Table 1. Of the 243 participants with baseline assessments, 51 had no follow-up data after three months post discharge resulting in an analytic sample of 192 in the three months follow-up analyses. The analytic sample of the twelve months follow-up analyses included 187 participants. A flowchart including a detailed description of the reason for missing data is provided in Additional File 1, Figure A1. In total, 39 patients $(16 \%)$ died during the study. These patients were older and had higher frailty and comorbidity index scores at baseline compared to patients with complete data for all assessments $(n=118)$ and patients lost to follow-up after twelve months $(n=$ 
Table 1 Baseline characteristics of baseline sample, the subsample used for the 3 months post discharge (T1) analyses, and the subsample used for the twelve months post discharge (T2) analyses

\begin{tabular}{|c|c|c|c|}
\hline \multirow[t]{2}{*}{ Baseline characteristics } & \multirow{2}{*}{$\begin{array}{l}\text { Baseline sample } \\
(n=243)\end{array}$} & \multirow{2}{*}{$\begin{array}{l}\text { T1 sample } \\
(n=192)\end{array}$} & \multirow{2}{*}{$\frac{\text { T2 sample }}{(n=187)}$} \\
\hline & & & \\
\hline Age, median (IQR 25;75) & $76(72 ; 81)$ & $76(72 ; 81)$ & $76(73 ; 81)$ \\
\hline range (years) & $70-98$ & $70-98$ & $70-98$ \\
\hline Sex, male & $165(68)$ & $132(69)$ & $129(69)$ \\
\hline \multicolumn{4}{|l|}{ Housing situation } \\
\hline independent & $225(93)$ & $179(93)$ & $173(93)$ \\
\hline not independent & $18(8)$ & $13(7)$ & $14(8)$ \\
\hline \multicolumn{4}{|l|}{ Education } \\
\hline$\leq$ high school & $173(71)$ & $140(73)$ & $132(71)$ \\
\hline$>$ high school & $70(29)$ & $52(27)$ & $55(29)$ \\
\hline CCI, median (IQR 25;75) & $2(1 ; 4)$ & $2(1 ; 4)$ & $2(1 ; 4)$ \\
\hline \multicolumn{4}{|l|}{ Frailty Index } \\
\hline median (IQR 25;75) & $0.18(0.08 ; 0.31)$ & $0.17(0.08 ; 0.30)$ & $0.18(0.08 ; 0.31)$ \\
\hline lowest possible score & $0(0)$ & $0(0)$ & $0(0)$ \\
\hline highest possible score & $0(0)$ & $0(0)$ & $0(0)$ \\
\hline \multicolumn{4}{|l|}{ Frailty Phenotype } \\
\hline median (IQR 25;75) & $1.00(0 ; 2.00)$ & $1.00(0 ; 2.00)$ & $1.00(0 ; 2.00)$ \\
\hline robust (0 criteria) & $97(40)$ & $81(42)$ & $74(40)$ \\
\hline prefrail (1 or 2 criteria) & $88(36)$ & $69(36)$ & $68(36)$ \\
\hline frail ( $\geq 3$ criteria) & $47(19)$ & $38(20)$ & $37(20)$ \\
\hline lowest possible score & $97(40)$ & $81(42)$ & $74(40)$ \\
\hline highest possible score & $4(2)$ & $3(2)$ & $4(2)$ \\
\hline
\end{tabular}

Notes: Values are presented as numbers and percentage (\%) unless indicated otherwise. Percentages may not equal $100 \%$ due to rounding and missing. CCl, Charlson Comorbidity Index; IQR, inter quartile range

56) (Additional File 2, Table S1). Between the latter two groups, no differences in baseline characteristics were found (Additional File 2, Table S1).

The FP showed a floor effect at baseline assessment, hampering detection of improvement in $40 \%$ of these patients (Table 1; Additional File 1, Figure A3). Mean scores of the frailty instruments at baseline and followup measurements for all and within collapsed categories as used in the analyses are presented in Table 2 and in Additional File 1, Table A3.

\section{Reproducibility}

ICCs, SEMs, and SDCs were presented in Table 3. ICC of the FI were 0.85 (95\% confidence interval [CI]: 0.76; 0.91 ) and 0.84 (95\% CI: 0.77; 0.90), and 0.65 (95\% CI: $0.49 ; 0.77)$ and 0.77 (95\% CI: $0.65 ; 0.84)$ for the FP. Kappa statistics of the FP categories were 0.41 (absolute agreement: 0.68 ) and 0.45 (absolute agreement: 0.70) indicating fair agreement (Additional File 1, Tables A4 A7). SEM of the FI were good to very good (5 and $6 \%$ ) and doubtful for the FP (11 and $13 \%$ ) (Table 3). Bland Altman plots are presented in the Additional File 1, Figures A4 and A5. Good agreement was observed for the FI using the functioning anchor and for the FP using the health and functioning anchors $(p>0.05)$. A systematic mean difference was observed between baseline and three-months follow-up tests of the FI using the health anchor (mean difference 0.02; $95 \%$ CI: 0.01; 0.03).

\section{Responsiveness}

All SRMs in the improved and deteriorated groups were higher than the SRMs in the stable (unchanged) groups, meaning that the measured change in frailty outcomes was lower among patients in the stable groups compared to patients in both the improved and deteriorated groups (Table 4). Largest SRMs were found for deterioration over twelve months (Table 4), with SRMs ranging from 0.69 to 1.00 , indicating good to very good internal responsiveness.

Only the FI showed sufficient responsiveness $(>0.70)$ to detect deterioration in frailty over three months (Fig. 1). Highest AUC of the FI was found for the health anchor question (AUC: 0.77; $95 \%$ CI: 0.69; 0.86, see Fig. 1). The optimal cut-off of the change scores from baseline to three months post discharge was 0.02 with corresponding sensitivity and specificity of 69 and $81 \%$ 
Table 2 Mean (SD) frailty scores at baseline (T0) and 3 months post discharge (T1)

\begin{tabular}{|c|c|c|c|c|c|}
\hline & \multicolumn{3}{|c|}{ Frailty Index } & \multicolumn{2}{|c|}{ Frailty Phenotype } \\
\hline & $\mathrm{n}$ & $\begin{array}{l}\text { T0 } \\
\text { mean (SD) }\end{array}$ & $\begin{array}{l}\mathrm{T} 1 \\
\text { mean (SD) }\end{array}$ & $\begin{array}{l}\text { T0 } \\
\text { mean (SD) }\end{array}$ & $\begin{array}{l}\mathrm{T1} \\
\text { mean (SD) }\end{array}$ \\
\hline \multicolumn{6}{|l|}{ Health anchor } \\
\hline \multicolumn{6}{|l|}{ All categories } \\
\hline much better & 24 & $0.19(0.12)$ & $0.13(0.09)$ & $1.38(1.28)$ & $0.35(0.65)$ \\
\hline slightly better & 24 & $0.23(0.19)$ & $0.22(0.20)$ & $1.57(1.27)$ & $1.00(1.18)$ \\
\hline more or less the same & 74 & $0.16(0.12)$ & $0.13(0.11)$ & $0.73(1.12)$ & $0.67(0.98)$ \\
\hline slightly worse & 34 & $0.19(0.15)$ & $0.22(0.16)$ & $0.97(1.36)$ & 1.09 (1.36) \\
\hline much worse & 36 & $0.32(0.17)$ & $0.60(0.25)$ & $2.14(1.40)$ & $3.60(1.79)$ \\
\hline \multicolumn{6}{|l|}{ Collapsed categories ${ }^{\mathrm{a}}$} \\
\hline improved & 48 & $0.21(0.16)$ & $0.17(0.16)$ & $1.48(1.27)$ & $0.68(1.00)$ \\
\hline unchanged & 74 & $0.16(0.12)$ & $0.13(0.11)$ & $0.73(1.12)$ & $0.67(0.98)$ \\
\hline deteriorated & 70 & $0.26(0.17)$ & $0.42(0.28)$ & $1.57(1.49)$ & $2.38(2.02)$ \\
\hline \multicolumn{6}{|l|}{ Functioning anchor } \\
\hline \multicolumn{6}{|l|}{ All categories } \\
\hline much better & 16 & $0.19(0.13)$ & $0.13(0.09)$ & $1.60(1.30)$ & $0.25(0.45)$ \\
\hline slightly better & 21 & $0.19(0.18)$ & $0.15(0.17)$ & $1.29(1.42)$ & $0.70(1.03)$ \\
\hline more or less the same & 80 & $0.17(0.14)$ & $0.16(0.14)$ & $0.78(1.15)$ & $0.74(0.99)$ \\
\hline slightly worse & 40 & $0.21(0.15)$ & $0.22(0.16)$ & $1.21(1.32)$ & $1.08(1.37)$ \\
\hline much worse & 35 & $0.32(0.15)$ & $0.61(0.23)$ & $2.12(1.39)$ & $3.82(1.57)$ \\
\hline \multicolumn{6}{|l|}{ Collapsed categories ${ }^{\mathrm{a} .}$} \\
\hline improved & 37 & $0.19(0.16)$ & $0.14(0.14)$ & $1.42(1.36)$ & $0.50(0.84)$ \\
\hline unchanged & 80 & $0.17(0.14)$ & $0.16(0.14)$ & 0.78 (1.15) & $0.74(0.99)$ \\
\hline deteriorated & 75 & $0.26(0.16)$ & $0.40(0.28)$ & $1.64(1.42)$ & $2.34(2.00)$ \\
\hline
\end{tabular}

${ }^{\mathrm{a}}$ The collapsed categories were used in the analyses of the health state and functioning anchor questions

(Additional File 1, Table A8). Over the timeframe of twelve month, both the FI and FP were responsive for deterioration in frailty status. Highest AUC's were found for the health anchor (AUC: 0.82; $95 \%$ CI: 0.73; 0.90 and AUC: $0.78 ; 95 \%$ CI: 0.69; 0.87) (Fig. 1) with corresponding optimal change score of 0.04 (Sensitivity: $75 \%$; Specificity: $77 \%$ ) and 0.50 (Sensitivity: $68 \%$; Specificity: $84 \%$ ) for the FI and FP, respectively (Additional File 1, Table A8). The FP consistently performed better in detecting improvement in frailty, yet all AUC values were below the threshold of 0.70 (Fig. 1).

Sensitivity analyses including complete cases only yielded essentially the same results. However, as expected, by disregarding the frailest individuals (Additional File 2, Table S1) and due to the smaller

Table 3 Reproducibility properties of unchanged patients at three months follow-up measurement

\begin{tabular}{|c|c|c|c|c|c|}
\hline \multicolumn{6}{|c|}{ Health anchor $(n=74)$} \\
\hline Instrument & ICC (95\% Cl) & SEM & SEM $\%^{a}$ & SDC & $\mathrm{SDC} \%^{\mathrm{a}}$ \\
\hline $\mathrm{FI}$ & $0.85(0.76 ; 0.91)$ & 0.05 & $5 \%$ & 0.13 & $13 \%$ \\
\hline FP & $0.65(0.49 ; 0.77)$ & 0.66 & $13 \%$ & 1.84 & $37 \%$ \\
\hline \multicolumn{6}{|c|}{ Functioning anchor $(n=80)$} \\
\hline Instrument & ICC $(95 \%$ Cl) & SEM & SEM $\%^{a}$ & SDC & SDC ${ }^{a}$ \\
\hline $\mathrm{FI}$ & $0.84(0.77 ; 0.90)$ & 0.06 & $6 \%$ & 0.16 & $16 \%$ \\
\hline FP & $0.77(0.65 ; 0.84)$ & 0.56 & $11 \%$ & 1.56 & $31 \%$ \\
\hline
\end{tabular}

Notes: Intraclass correlation coefficient for agreement using a 2 way mixed effect model. ICC Intraclass Correlation Coefficient, FI Frailty Index; FP Frailty Phenotype; SDC smallest detectable change; SEM standard error of measurement.

a. SEM\% and SDC\% are SEM and SDC expressed in percentages of the continuous score of the instrument 
Table 4 Mean change scores and internal responsiveness for improved, unchanged, and deteriorated patients

\begin{tabular}{|c|c|c|c|c|c|c|}
\hline \multirow[t]{2}{*}{ Health anchor } & \multicolumn{3}{|c|}{3 months post discharge $(n=192)$} & \multicolumn{3}{|c|}{12 months post discharge $(n=187)$} \\
\hline & mean change score (SD) & Correlation & SRM & Mean change score (SD) & Correlation & SRM \\
\hline \multicolumn{7}{|l|}{ Frailty Index } \\
\hline improved & $-0.05(0.11)$ & 0.48 & -0.45 & $-0.07(0.12)$ & 0.61 & -0.58 \\
\hline unchanged & $-0.02(0.06)$ & & -0.33 & $-0.01(0.08)$ & & -0.13 \\
\hline deteriorated & $0.16(0.23)$ & & 0.70 & $0.27(0.27)$ & & 1.00 \\
\hline \multicolumn{7}{|l|}{ Frailty Phenotype } \\
\hline improved & $-0.86(1.21)$ & 0.46 & -0.71 & $-0.93(1.38)$ & 0.57 & -0.67 \\
\hline unchanged & $-0.05(0.88)$ & & -0.06 & $-0.18(0.86)$ & & -0.21 \\
\hline deteriorated & $0.82(1.67)$ & & 0.49 & $1.60(2.00)$ & & 0.80 \\
\hline \multirow[t]{2}{*}{ Functioning anchor } & \multicolumn{3}{|c|}{3 months post discharge $(n=192)$} & \multicolumn{3}{|c|}{12 months post discharge $(n=187)$} \\
\hline & mean change score (SD) & Correlation & SRM & Mean change score (SD) & Correlation & SRM \\
\hline \multicolumn{7}{|l|}{ Frailty Index } \\
\hline improved & $-0.06(0.11)$ & 0.43 & -0.55 & $-0.08(0.13)$ & 0.57 & -0.62 \\
\hline unchanged & $-0.01(0.06)$ & & -0.16 & $-0.01(0.09)$ & & -0.11 \\
\hline deteriorated & $0.13(0.23)$ & & 0.57 & $0.23(0.27)$ & & 0.85 \\
\hline \multicolumn{7}{|l|}{ Frailty Phenotype } \\
\hline improved & $-0.94(1.31)$ & 0.47 & -0.72 & $-1.17(1.46)$ & 0.57 & -0.80 \\
\hline unchanged & $-0.09(0.73)$ & & -0.12 & $-0.24(1.01)$ & & -0.24 \\
\hline deteriorated & $0.74(1.73)$ & & 0.43 & $1.36(1.96)$ & & 0.69 \\
\hline
\end{tabular}

Notes: Spearman correlation coefficients were calculated by using the mean change scores of the total group and the anchor question. Abbreviations: $S D$ standard deviation; SRM standardized response mean

sample, the AUC values regarding deterioration were lower in this subgroup (Additional File 2, Figure S1).

\section{Discussion}

In this study on acutely hospitalized older medical patients, we found that the FI showed good reproducibility and the FP showed moderate reproducibility. In addition, the FI was responsive in detecting deterioration in frailty between pre-acute hospital admission and three and twelve months post discharge. The FP was only responsive in detecting patients with deteriorating frailty status between pre-hospital admission and twelve months post-discharge.

Like cholesterol is a measurable marker for cardiovascular disease risk and HbA1c for risk of complications of diabetes type 2, frailty can be considered as the measurable marker for risk of adverse outcomes. Responsive frailty measures can therefore act as an important intermediate outcome for the evaluation of interventions aiming at preventing adverse health outcomes in older patients. Despite that the FP is frequently used as an outcome instrument to evaluate interventions, we failed to establish satisfactory reproducibility and responsiveness of the FP over a three months timeframe [24-26]. In addition, a floor effect of the FP was found in $40 \%$ of the cases. This may have led to an underestimation of the ability to detect improvements, but it may have overestimated the results based on the unchanged patients.
Consequently, the reproducibility outcomes may have been even overestimated due to the floor effect of the FP. Although, in theory, an instrument can be responsive with a low validity or reliability, it may be undesirable to use such an instrument to measure change over time [27]. Consequently, despite the apparently better outcomes of the FP compared to the FI to measure improvements in frailty status over time, we have substantial reservations to draw this conclusions due to the unsatisfactory reproducibility outcomes of the FP in the current study. In addition, the practical applicability of the FP to measure improvement over time is limited by the presence of a floor effect of the FP.

In the current study, an increase of five deficits over three months and six deficits over twelve months corresponds with the smallest detectable change of the FI that is meaningful to patients. The found change scores are higher than reported in recent other studies investigating clinically meaningful change of the FI [28, 29]. These differences may be explained by the used anchor: in the current study a subjective perception of change in health and functioning according to the patient was used, whereas the other studies used existing instruments, like the EQ-5D and the Clinical Frailty Scale, as the external anchor. Our participants could have been adapted to their changed health state after hospitalization [30] 


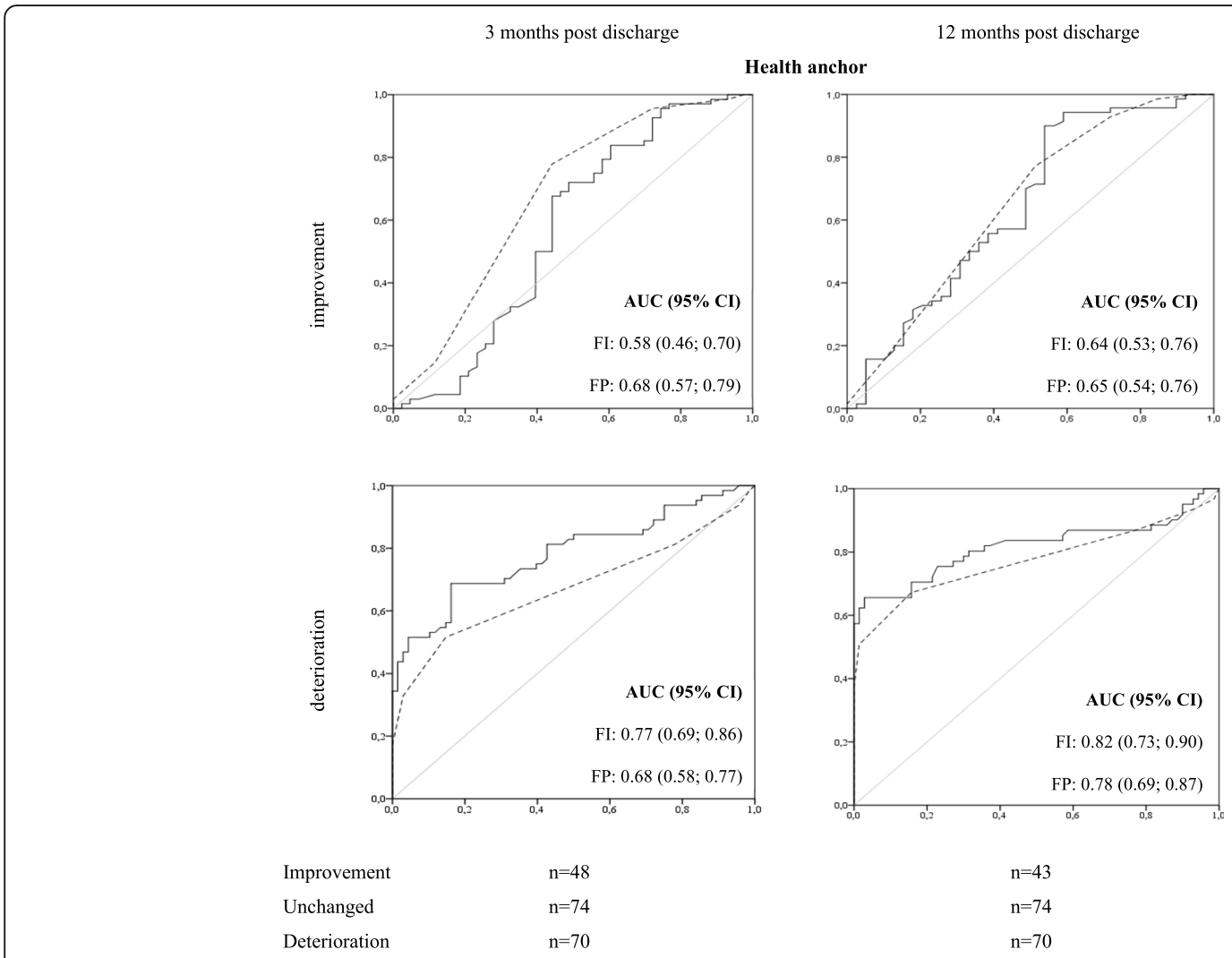

Functioning anchor
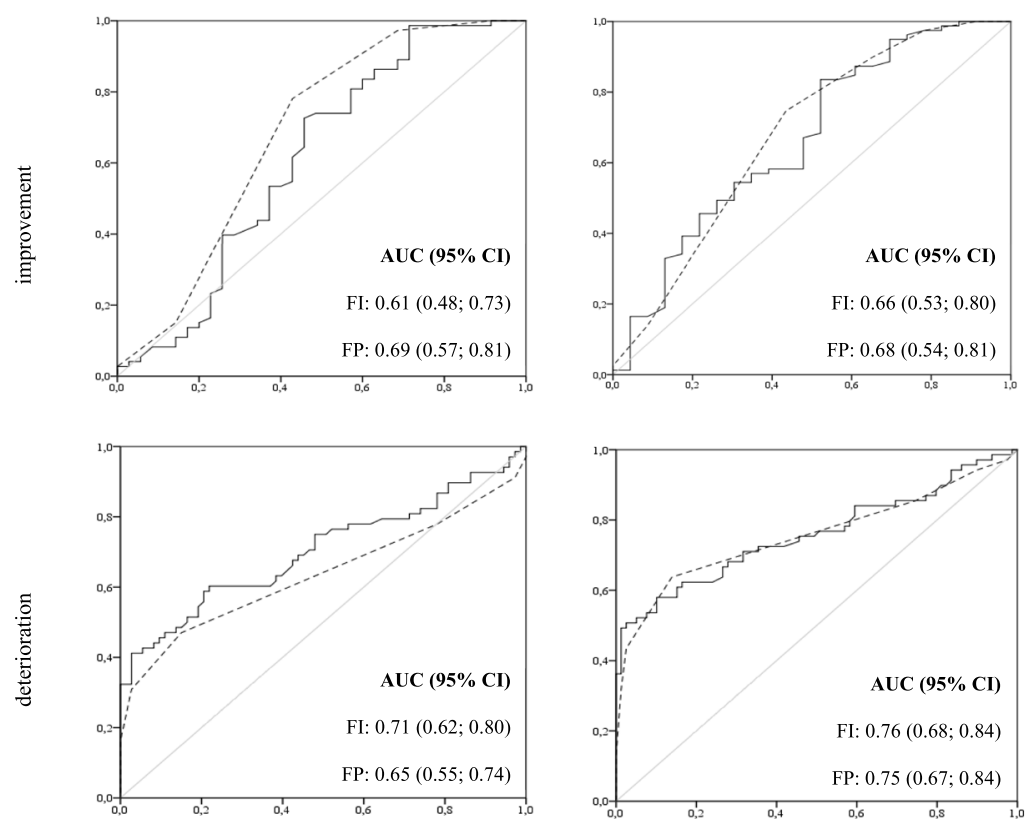

Improvement
Unchanged
Deterioration

$\mathrm{n}=37$

$\mathrm{n}=26$

$\mathrm{n}=80$

$\mathrm{n}=80$

$\mathrm{n}=81$

Fig. 1 (See legend on next page.) 
(See figure on previous page.)

Fig. 1 Receiver Operating Characteristic (ROC) curve comparisons and corresponding Area Under the ROC curves (AUC) between the Frailty Index (solid line) and the Frailty Phenotype (dashed line) for measuring improvement and deterioration in frailty status according to the health and functioning anchor questions after three (left) and twelve (right) months post discharge. The diagonal lines (gray) represent the reference lines of no-discrimination

which may have resulted in a larger change score that is regarded meaningful to patients themselves. However, patients who perceived no change in health and functional status after three and twelve months post discharge, also had the smallest change scores on the frailty instruments. Another explanation may be that the change in frailty status according to a clinician which was investigated by Theou and colleagues [29] is different from the patients perception of change in frailty status as investigated in the current study.

Strengths of this study are the use of various methods for assessing reproducibility and responsiveness and the large sample size. More than twice the recommended number of patients for evaluating psychometric properties were included [19]. There are, however, limitations. First, instead of using a comprehensive geriatric assessment, the gold standard for frailty status, we used two relevant patient-based anchor questions to determine change in frailty. By using two anchor questions referring to change in function and health in a population that is prone to frailty, we intended to come close to evaluating real frailty status. The moderate positive correlations of these anchor questions with the change scores on the frailty instruments indicate that the chosen anchor questions may not fully capture the whole concept of frailty. Directly asking for change in frailty was, however, not an option because older adults themselves are not familiar with this concept [31]. Second, the design for determining the reproducibility of the frailty instruments was not ideal. On the one hand, the time interval between the test and the retest, three months, is a long period to assume that the patients have remained stable. In addition, stability was based on self-reported, thus subjective, anchor questions, which did show a moderate correlation with the change scores on the frailty instruments (ranging from 0.43 to 0.48 ). Although mean change scores and standard deviations were smallest in the unchanged subgroups, suggesting little variation in frailty scores between the first and second assessments and suggesting clinically stable patients, the gold standard for measuring frailty was unavailable and objective clinical stability could not be guaranteed. However, if some unstable patients were inadvertently considered stable in the current study, the found reproducibility scores are expected to be an underestimation of the "real" reliability. Third, we cannot rule out that the results are biased by response shift, as response shift evaluation was not incorporated in the study design
[30]. Fourth, the modified FP was used instead of the original performance-based measures because in our population of older medical patients, performance-based assessment is often too challenging and would have led to the inclusion of the fittest frail patients, resulting in an undesirable selection bias. Fifth, due to ethical considerations, no patients were included with cognitive impairment due to dementia or delirium, although frailty in these patients is often present and their frailty status is expected to decline after hospitalization. However, the broad inclusion criteria still resulted in the inclusion of a representative sample of the geriatric population consisting of a heterogeneous group of mentally competent older medical patients.

Future research should compare the responsiveness of existing frailty instruments and their relation to the course of functional impairment in multiple studies and other patient groups with a reliable gold standard for the measurement of frailty. These studies should also incorporate measures such as a then-test in study designs to identify and adjust for response shift.

\section{Conclusions}

In this study, the Frailty Index showed better reproducibility and responsiveness properties compared to the Frailty Phenotype. Based on this single study we cannot yet formulate concrete recommendations about the best instrument to evaluating frailty status over time that is meaningful to older patients.

\section{Abbreviations}

AUC: Area Under the receiver operating Curve; CCl: Charlson Comorbidity Index; Cl: Confidence Interval; ICC: Intra-class Correlation Coefficient; IQR: Inter Quartile Range; FI: Frailty Index; FP: Frailty Phenotype; SD: Standard Deviation; SDC: Smallest Detectable Change; SEM: Standard Error of Measurement; SRM: Standardized Response Mean

\section{Supplementary Information}

The online version contains supplementary material available at https://doi. org/10.1186/s12877-021-02444-y.

Additional file 1: Table A1. List of items Frailty Index. Table A2. List of the criteria and items Frailty Phenotype. Figure A1. Flowchart of subjects. Figure A2. Baseline distribution and frequency of Frailty Index scores. Figure A3. Baseline distribution and frequency Frailty Phenotype scores. Table A3. Mean scores for all and collapsed categories at 12 months follow-up. Figure A4. Bland Altman plots health anchor. Figure A5. Bland Altman plots functioning anchor. Table A4. Cross table Frailty Phenotype and the health anchor. Table A5. Kappa statistic Frailty Phenotype health anchor. Table A6. Cross tables Frailty Phenotype and functioning anchor. Table A7. Kappa statistic Frailty Phenotype 
functioning anchor. Table A8. External responsiveness, AUC, sensitivity and specificity at 12 months follow-up.

Additional file 2: Sensitivity analysis including. Table S1. Complete case analysis: Baseline characteristics. Table S2. Complete case analysis: Reproducibility properties of unchanged patients at three months followup measurement. Table S3. Complete case analysis: Mean change scores and internal responsiveness for improved, unchanged, and deteriorated patients. Figure S1. Complete Case Analysis: Receiver Operating Characteristic (ROC) curve comparisons and corresponding Area Under the ROC curves (AUC).

\section{Acknowledgements}

The authors also wish to acknowledge all the research assistants for their assistance with data collection and all study participants for their time.

\section{Authors' contributions}

SER, CJJ, MF coordinated the acquisition of subjects, data collection, and processing. MF and CJJ performed the initial statistical analyses. MF and FMMO wrote the first draft of the manuscript and performed the additional analyses and adjustments during the revision process. NS, BCM and SER aided in interpreting the results. All authors were involved in the study design, revising manuscript draft for important intellectual content, and gave approval for the final manuscript, and thereby taking full responsibility for the work and manuscript content.

\section{Funding}

None.

\section{Availability of data and materials}

The datasets used during the current study are available from the corresponding author upon reasonable request.

\section{Declarations}

\section{Ethics approval and consent to participate}

The Research Ethics Committee of the University Medical Center Groningen approved the study protocol and ruled that no formal ethics approval was required (file number: 201600268). Written informed consent of all participants was obtained before participation.

\section{Consent for publication}

Not applicable.

\section{Competing interests}

The authors declare they have no competing interests.

\section{Author details}

'Department of Internal Medicine and Geriatrics, University of Groningen, University Medical Center Groningen, PO Box 30001, HPC: AA43, 9700 RB Groningen, The Netherlands. ${ }^{2}$ Medical Spectrum Twente Hospital, Enschede, the Netherlands. ${ }^{3}$ Department of Geriatrics, Gelre Hospitals, Apeldoorn, The Netherlands. ${ }^{4}$ Department of Epidemiology, University of Groningen, University Medical Center Groningen, Groningen, The Netherlands.

Received: 11 October 2020 Accepted: 6 September 2021

\section{Published online: 17 September 2021}

\section{References}

1. Clegg A, Young J, lliffe S, Olde Rikkert MGM, Rockwood K. Frailty in older people summary. Lancet. 2013;381(9868):752-62.

2. Joosten E, Demuynck M, Detroyer E, Milisen K. Prevalence of frailty and its ability to predict in hospital delirium, falls, and 6-month mortality in hospitalized older patients. BMC Geriatr. 2014;14(1):1-9.

3. Vu HT, Nguyen TX, Nguyen TN, Nguyen AT, Cumming R, Hilmer SN, et al. Prevalence of frailty and its associated factors in older hospitalised patients in. BMC Geriatr. 2017;17(216):1-7.

4. Apóstolo J, Cooke R, Bobrowicz-campos E, Santana S, Marcucci M, Cano A, et al. Effectiveness of interventions to prevent pre-frailty and frailty progression in older adults: a systematic review. JBI Database Syst Rev Implement Rep. 2018;16(1):140-232.
5. Dedeyne L, Deschodt M, Verschueren S, Tournoy J, Gielen E. Effects of multi-domain interventions in (pre)frail elderly on frailty, functional, and cognitive status: A systematic review. Clin Interv Aging. 2017;12:873-96.

6. Rockwood K, Theou O, Mitnitski A. What are frailty instruments for? Age Ageing. 2015;44(4):545-7.

7. Buta BJ, Walston JD, Godino JG, Park M, Kalyani RR, Xue Q, et al. Frailty assessment instruments: Systematic characterization of the uses and contexts of highly-cited instruments. Ageing Res Rev. 2017;March(26): 53-61.

8. Morley JE, Vellas B, Kan GA, Van, Anker SD, Bauer JM, Bernabei R, et al. Frailty Consensus: A Call to Action. J Am Med Dir Assoc. 2013;14(6):392-7.

9. Drubbel I, Numans ME, Kranenburg G, Bleijenberg N, Wit NJ, De. Screening for frailty in primary care: a systematic review of the psychometric properties of the frailty index in community-dwelling older people. BMC Geriatr. 2014;14(1):1-13.

10. Sutton JL, Gould RL, Daley S, Coulson MC, Ward EV, Butler AM, et al. Psychometric properties of multicomponent tools designed to assess frailty in older adults: A systematic review. BMC Geriatr. 2016;16:1.

11. De Vries NM, Staal JB, Van Ravensberg CD, Hobbelen JSM, Olde Rikkert MGM. Nijhuis-van der Sanden MWG. Outcome instruments to measure frailty: a systematic review. Ageing Res Rev. 2011;10:104-14.

12. Apostolo J, Cooke R, Bobowicz-Campos E, Santana S, Marcucci M, Cano A, et al. Predicting risk and outcomes for frail older adults: an umbrella review of frailty screening tools '. JBI Database Syst Rev Implement Rep. 2017;15(4): 1154-208.

13. Kamper SJ, Maher CG, Mackay G. Global rating of change scales: A review of strengths and weaknesses and considerations for design. J Man Manip Ther. 2009;17(3):163-70

14. Searle SD, Mitnitski A, Gahbauer EA, Gill TM, Rockwood K. A standard procedure for creating a frailty index. BMC Geriatr. 2008;8(1):24.

15. Fried LP, Tangen CM, Walston J, Newman AB, Hirsch C, Gottdiener J, et al. Frailty in older adults: Evidence for a phenotype. Journals Gerontol Ser aBiological Sci Med Sci. 2001;56(3):M146-56.

16. Theou O, Rockwood K. Comparison and Clinical Applications of the Frailty Phenotype and Frailty Index Approaches. Interdiscip Top Gerontol Geriatr. 2015:41:74-84.

17. de Vet HC, Bouter LM, Bezemer PD, Beurskens AJ. Reproducibility and responsiveness of evaluative outcome measures. Theoretical considerations illustrated by an empirical example. Int J Technol Assess Health Care. 2001; 17(4):479-87.

18. Charlson ME, Pompei P, Ales KL, Mackenzie CR. A new method of classifying prognostic comorbidity in longitudinal studies: Development and validation. J Chronic Dis. 1987;40(5):373-83.

19. De Vet HCW, Terwee CB, Knol DL, Mokkink LB. Measurement in Medicine. first. Cambridge: Cambridge University Press; 2011. 347 p.

20. Koo TK, Li MY. A Guideline of Selecting and Reporting Intraclass Correlation Coefficients for Reliability Research. J Chiropr Med. 2016;15(2):155-63.

21. Ostelo RWJG, De Vet HCW, Knol DL, Van Den Brandt PA. 24-Item RolandMorris Disability Questionnaire was preferred out of six functional status questionnaires for post-lumbar disc surgery. J Clin Epidemiol. 2004;57(3): 268-76.

22. Cohen J. Statistical Power Analysis for the Behavioral Sciences. New York: Academic Press; 1977.

23. Akoglu H. User's guide to correlation coefficients. Turkish J Emerg Med. 2018;18(3):91-3.

24. Hars M, Herrmann FR, Fielding RA, Reid KF, Rizzoli R, Trombetti A. LongTerm Exercise in Older Adults: 4-Year Outcomes of Music-Based Multitask Training. Calcif Tissue Int. 2014;95(5):393-404.

25. Tarazona-Santabalbina FJ, Gómez-Cabrera MC, Pérez-Ros P, Martínez-Arnau FM, Cabo H, Tsaparas K, et al. A Multicomponent Exercise Intervention that Reverses Frailty and Improves Cognition, Emotion, and Social Networking in the Community-Dwelling Frail Elderly: A Randomized Clinical Trial. J Am Med Dir Assoc. 2016;17(5):426-33.

26. Ng TP, Feng L, Nyunt MSZ, Feng L, Niti M, Tan BY, et al. Nutritional, Physical, Cognitive, and Combination Interventions and Frailty Reversal among Older Adults: A Randomized Controlled Trial. Am J Med. 2015;128(11):1225-36.e1.

27. Hays RD, Hadorn D. Responsiveness to change: an aspect of validity, not a separate dimension. Qual Life Res. 1992;1 (1):73-5.

28. Jang IY, Jung HW, Lee HY, Park H, Lee E, Kim DH. Evaluation of Clinically Meaningful Changes in Measures of Frailty. J Gerontol A Biol Sci Med Sci. 2020;75(6):1143-7. 
29. Theou O, van der Valk AM, Godin J, Andrew MK, McElhaney JE, McNeil SA, et al. Exploring clinically meaningful changes for the frailty index in a longitudinal cohort of hospitalized older patients. Journals Gerontol - Ser A Biol Sci Med Sci. 2020;75(10):1928-34.

30. Barclay-Goddard R, Epstein JD, Mayo NE. Response shift: A brief overview and proposed research priorities. Qual Life Res. 2009;18(3):335-46.

31. Durepos P, Sciences HH, Alsbury K, Hewston P, Borges J. Older Adults ' Perceptions of Frailty Language: A Scoping Review. ResearchGate. 2020; (January).

\section{Publisher's Note}

Springer Nature remains neutral with regard to jurisdictional claims in published maps and institutional affiliations.

Ready to submit your research? Choose BMC and benefit from:

- fast, convenient online submission

- thorough peer review by experienced researchers in your field

- rapid publication on acceptance

- support for research data, including large and complex data types

- gold Open Access which fosters wider collaboration and increased citations

- maximum visibility for your research: over $100 \mathrm{M}$ website views per year

At $\mathrm{BMC}$, research is always in progress.

Learn more biomedcentral.com/submissions 